\title{
REVISITANDO CONCEITOS DE AQUISIÇÃO DE L2: DEFENDENDO PROPOSTAS TEÓRICAS ABRANGENTES
}

\author{
Roberto de FREITAS JÚNIOR \\ (Faculdade Gama e Souza) \\ robertofrei@hotmail.com
}

Resumo: $O$ artigo se dedica a apresentar e discutir conceitos relevantes na área de aquisição de L2 com a finalidade de, após o levantamento dos aspectos teóricos e conceituais relacionados à área, questionar uma tendência frequente no âmbito da linguística, principalmente teórica, de restringir as explicações acerca dos fenômenos emergentes no contexto de aquisição, a paradigmas teóricos específicos e que nem sempre apresentam sozinhos soluções plausíveis para tais questões.

Palavras-Chave: Aquisição de L2. Interferência. Transferência.

\section{REVISITING SECOND LANGUAGE AQUISITION CONCEPTS: IN DEFENSE OF BROAD THEORITICAL PROPOSTIONS}

Abstract: The article is devoted to presenting and discussing relevant concepts in the area of SLA in order to, after revisiting theoretical and conceptual aspects related to the area, debate on a very common trend in linguistics, that is to restrict explanations of emergent linguistic phenomena in the context of SLA solely to specific theoretical paradigms that are not always able to provide plausible solutions to such issues.

Keywords: SLA. Interference. Language Transfer. 
O avanço das pesquisas de aquisição de segunda língua (SLA - Second Language Aquisition) ainda não possibilitou a explicação da questão em sua amplitude. Linguistas há muito debatem sobre a influência tanto de um suposto conhecimento linguístico anterior do aprendiz (CHOMSKY, 1961), como de sua competência comunicativa (HYMES, 1974), ao longo do processo de aprendizagem. Na verdade, sobre o processo de aquisição/aprendizado de um segundo idioma, o que as pesquisas mostram é que ele ainda se revela um importante e vasto campo de investigação, longe de ser plenamente explicado. Tal discussão se torna especialmente importante, em particular em tempos de globalização e de uso expressivo de segundas línguas (L2), com destaque para o inglês, para fins comunicativos diversos.

Teorias de SLA buscam o entendimento do desenvolvimento da interlíngua, aquela modalidade linguística que seria 0 produto do usuário/aprendiz e que possui marcas próprias, em geral, mesclas da L1 e da L2 em questão. Sendo assim, entra em jogo o papel exercido por universais linguísticos, comunicativos e dos ambientes de aprendizagem/aquisição, dentre outros fatores. Por serem em grande número, em geral, elas divergem e terminam por fornecer descrições parciais de um fenômeno maior. A recente literatura em SLA, entretanto, já fornece evidências fortes sobre os fatores mais salientes para a formulação de qualquer teoria de aquisição de uma L2.

Seriam vários os fatores relevantes para a formação de uma teoria nessa área. Uma teoria de SLA deve considerar, para além de fatores de ordem estritamente linguística e/ou comunicativa, o papel do aprendiz e suas especificidades e habilidades de aprendizado (p.ex.: inteligência), além de sua motivação e atitude frente ao idioma, fatores que interagem e influenciam o desenvolvimento da interlíngua (cf. LONG, 1994, p. 479).

Além desses, os papéis do input da L2 e do ambiente em que acontece o processo de aquisição também são tidos como relevantes para o processo de formação da interlíngua. Por fim, destaca-se o papel da L1 através de transferências que podem auxiliar, ou mesmo dificultar, o processo aquisitivo e a interação verbal na língua alvo (LA).

Todas essas variáveis apontam para a própria conceituação da interlíngua, visto que aprendizes de diferentes idades e graus de instrução traçam trajetórias desenvolvimentais semelhantes em função da aquisição do 
sistema da L2, apresentando, sempre, uma variabilidade de usos aparentemente caótica, porém governada por algum sistema subjacente de regras e princípios que podem explicar aquilo que parece não ser organizado. (LONG, 1994, p. 480).

$\mathrm{Na}$ presente proposta, assumimos a perspectiva de que o indivíduo aprende uma L2, e não exatamente a adquire, sendo, por consequência, a gramática emergente nesse contexto, por mais próxima que possa ser do modelo nativo, um conjunto estrutural-discursivo particular e não biologicamente/cognitivamente determinado tal como seria a L1. Este sistema, em alguma medida, dependendo dos fatores atuantes em sua formação, apresentará características da L1 do aprendiz e da LA, além de estruturas nem sempre aceitáveis em nenhum dos dois sistemas, fenômeno comum nesse tipo de gramática.

Nesse sentido, a interlíngua seria um recorte adaptado de um sistema linguístico, o qual é, potencialmente falando, um modelo a ser adquirido/aprendido. Seria ela construída em diferentes fases e com características fonético-fonológicas, lexicais, morfossintáticas e discursivas que muitas vezes são distorções e agramaticalidades na L2, podendo comprometer a inteligibilidade do processo comunicativo.

Portanto, embora ao longo do presente artigo utilizemos o termo 'aquisição', ressaltamos que não entendemos o processo aquisitivo de uma L2 como possível, dado ser incompleto, já que os usuários de L2 não fornecem evidências de que, de fato, adquiram, de modo absoluto, uma gramática, além de sua própria L1, o que seria evidenciado, como já dito, por fatores de diferentes naturezas, como a identidade e língua do usuário, a memória, a cognição, além das experiências linguísticas e de mundo que parecem atuar no processo de aprendizado de uma L2.

\section{A questão da transferência L1-L2}

A discussão acerca da transferência L1-L2 é controversa no sentido de sua aceitação quanto a ser importante para os estudos de SLA, posto não ser a transferência nem sempre suficiente para explicar diferentes fenômenos presentes na aquisição de diferentes línguas (cf. ODLIN, 1989,3). Apesar de 
possíveis contra-argumentos para a importância de estudos de transferência, pesquisadores na área de SLA reconhecem sua relevância e mostram que, embora talvez não expliquem todos os fatores relacionados à questão da aquisição, eles representam forte contribuição para o entendimento de várias questões relacionadas ao assunto. De certa forma, as pessoas recorrem a estruturas cognitivas complexas para dar conta de suas necessidades comunicativo-interacionais em L2 e a transferência é um caminho que quase sempre surge para a execução desta tarefa.

O conceito de transferência sofreu transformações ao longo da história dos estudos de SLA. Data da proposta audiolingual, de base behaviorista, o conceito de interferência, mais tarde reformulado, no âmbito da proposta inatista, por transferência paramétrica. Essa proposta é hoje reconhecida por ser, ao menos parcialmente, responsável pela formação da interlíngua. Diferentemente, como já dito, GIVÓN (1979) ainda abarca, no que formula por modo pragmático de comunicação, forças pragmáticas oriundas do discurso presentes na sintaxe do segundo idioma. Enfim, propostas formalistas, funcionalistas, sociocognitivas já se propuseram a explicar, dada sua importância, a questão da transferência para os estudos e teorias de SLA.

Divergências nos estudos de transferência são originárias, por exemplo, da impossibilidade de generalizações sobre a discussão aquisição/aprendizado da L2. Questões tais como a Hipótese do Período Crítico (LENNEBERG, 1967) e a da Fossilização (SELINKER \& LAMENDELLA, 1979) podem evidenciar tais diferenças.

\section{Transferência, interferência, generalização e supergeneralização}

A literatura de SLA apresenta dois termos que se destacam como fenômenos recorrentes na aquisição de uma L2: a transferência e a generalização. Embora sejam processos distintos, eles se aproximam no sentido de serem manifestações de um mesmo princípio: o do encontro de material já adquirido com o material em processo de aquisição.

Para Brown $(1994,90)$, a transferência é um termo geral que abarca o uso de conhecimentos prévios no aprendizado da L2. Quando o conhecimento auxilia o aprendizado, temos transferência positiva, mas quando o deturpa, é 
considerada negativa e é traduzida, principalmente pela abordagem behaviorista, como interferência. No passado muitos entendiam a aquisição de um segundo idioma como a superação de efeitos 'negativos' transpostos da L1.

Neste cenário, emerge a Hipótese da Análise Contrastiva (CAH Contrastive Analysis Hypothesis) que, enraizada na noção behaviorista de condicionamento de hábitos e na abordagem linguística estruturalista, vigente em sua época, apontava a interferência da L1 como o fator inibidor mais importante para o comprometimento do aprendizado de uma L2. Para a CAH, uma abordagem científica e estruturalista das duas línguas em questão permitiria apontar suas diferenças e contrastes e assim prever o que poderia ser objeto de dificuldade para o aprendiz (BROWN, 1994, p. 193). Da mesma forma, seriam previsíveis ambientes que não favoreceriam a interferência e não dificultariam a aquisição. Logo, a influência da língua materna representaria a influência de hábitos anteriores do aprendiz, alguns potencialmente úteis e outros potencialmente perigosos para o processo de aquisição.

A generalização aponta para o papel do indivíduo como ator importante em seu próprio processo de aprendizagem. A partir de regras e conhecimentos já adquiridos, o falante de uma L2 poderá apresentar dados novos no uso da LA, sem comprometimento de sentidos por não serem estes erros na língua de aquisição.

A partir dos anos 70, segundo ODLIN (1989, p. 17), a análise contrastiva passa a ser questionada, principalmente devido à evolução dos estudos empíricos sobre transferência e de análise de erros. Dentre as causas para seu questionamento apontamos:

a) as diferenças entre línguas que nem sempre representam importante dificuldade de aprendizado;

b) a ocorrência de erros que não parecem ser explicados por influência da L1, mas por universais linguísticos empíricos;

c) a ocorrência de erros que não parecem ser explicados por influência da L1, mas por influência de como o aluno é ensinado - erros induzidos (cf. Stenson, 1974), e

d) a ocorrência de erros espontâneos - overgeneralizations. 
Assim, apesar de a CAH apresentar evidências de influência da $L 1$, a comparação da L1 com a LA só seria útil, se feita para explicar a previsibilidade de ocorrência de certos tipos de erros, e ainda assim, segundo ODLIN (1989, p. 19), sem dados reais dos erros dos aprendizes, pouco pode ser realmente considerado previsível.

Se a generalização diz respeito a nossa habilidade de, a partir de inferência de regras e leis aprendidas, projetar conhecimentos anteriores em contextos novos em que as regras se adaptam, o termo overgeneralization (supergeneralização de regras) é usado na referência de aplicação de regras em contextos em que elas não são necessárias, ou nem mesmo permitidas.

A transferência, positiva ou negativa, a generalização e a supergeneralização, em certos estágios da aquisição de L2, podem, ou não, ser processos considerados específicos dessas fases, embora não exclusivas do curso de aquisição de $L 2$, já que estudos em diferentes línguas mostram a generalização e a supergeneralização, por exemplo, acontecendo com aprendizes de diferentes L1.

Além do mais, muitos linguistas defendem que, se na aquisição da língua materna 0 indivíduo apresenta diferentes estágios desenvolvimentais, este mesmo fato poderia sugerir a influência de outros fatores no processo de SLA, tais como a atuação de universais de aquisição os quais seriam também responsáveis por estágios desenvolvimentais da L2.

\section{Visões sobre a transferência}

A transferência ainda pode ser tratada segundo a Teoria de Princípios e Parâmetros (CHOMSKY, 1981), doravante TPP, a partir de pressupostos de orientação sociolinguística ou de abordagens comunicativas (GIVÓN, 1979).

\section{Gramática universal, parâmetros e transferência}

A proposta gerativista trata da possível atuação da Gramática Universal e da transferência paramétrica na aquisição de uma L2. Para a teoria formal, a arquitetura da linguagem é inata, é inerente ao homem e responsável pelo 
aprendizado das línguas, via exposição prévia da criança aos dados do input do L1.

A aquisição acontece, então, pela exposição à língua e graças a um dispositivo de aquisição da linguagem (LAD - Language Acquisition Device), também específico do homem. Segundo White (1993:452), a GU consiste em princípios fixos que perpassam o conhecimento do falante nativo e em parâmetros, princípios variantes de língua para língua. A aquisição é determinada pela exposição à determinada língua, o que funciona como 'gatilho' para a fixação de seus parâmetros específicos.

Esta proposta atrai especial atenção dos estudiosos no campo de aquisição de L2, por fornecer subsídios para explicar o conhecimento subjacente do falante - sua 'competência linguística - e para investigar a atuação da GU no processo de aquisição.

Se o argumento da 'pobreza de estímulo' justifica a atuação, ou mesmo existência, da GU na aquisição da L1, segundo gerativistas, ele também poderia justificar sua existência na aquisição de uma L2, visto que, assim como o falante nativo apresenta um nível representacional na língua materna anterior ao seu input, assim também o faz o aprendiz de uma L2.

White (1993, p. 453) mostra que é inevitável considerarmos a possível transferência de fatores da L1 ao longo do processo de SLA mesmo em uma abordagem em que se considere a atuação da GU. Ainda assim, tal como ocorre na aquisição de uma L1, em uma abordagem que contemple a atuação da GU na aquisição de uma L2, pode estar implícita a ideia de que a atuação dos princípios universais não seja acompanhada de fenômenos que remetam à questão da transferência.

De qualquer forma, segundo a autora, traços paramétricos podem significar a explicação para a interpretação de diferenças entre a L1, a L2 e a interlíngua. Assim, as propostas vigentes seriam duas:

a) se a GU estiver disponível na aquisição da L2, a partir dos parâmetros da L1 poderíamos explicar e prever fenômenos de transferência, pois os indivíduos poderiam transferir o valor dos parâmetros da L1 para a L2;

b) por outro lado, a transferência também pode ser argumento contra a atenção da GU na SLA, se considerarmos que, se os aprendizes somente são capazes de adotar os princípios e parâmetros da $L 1$, isso indicaria que o suposto acesso 
à GU seria parcial, ou mesmo nulo, determinando uma diferença importante entre os processos de aquisição de L1 e de L2.

A teoria inatista passa a ser, portanto, uma possível fonte para 0 entendimento da questão da transferência na aquisição de uma L2, por inserir, ou não, a atuação da GU no conjunto de fatores que podemos apontar como relevantes na SLA. Este fato retoma a discussão acerca da aquisição ou aprendizagem de uma L2, já que a não atuação da GU seria a explicação a favor do aprendizado e não aquisição de uma língua materna.

\section{A transferência paramétrica}

As pesquisas formalistas recentes sobre SLA enfatizam, então, a possível influência dos parâmetros da L1 na aquisição da L2. Contudo, os pesquisadores gerativistas diferem, em termos gerais, quanto à precisa influência da L1 no campo da aquisição (WHITE, 1993, p. 454). A primeira diferença diz respeito à crença de que os parâmetros da L1 sejam a base para a interpretação dos dados da L2. Ou seja, a crença de que eles estão presentes na interlíngua do aprendiz até que ele tenha este parâmetro remarcado segundo a perspectiva da língua adquirida. A segunda diz respeito à crença de que os parâmetros da L1 não são efetivamente transferidos e realizados na interlíngua, mas atrasam a marcação do parâmetro da L2. Neste caso, não fica claro qual é, então, a natureza da interlíngua, se ela é influenciada pela GU, pela L1, ou outra possibilidade.

Associar a questão da transferência L1-L2 à TPP poderia parecer mera atualização da antiga $\mathrm{CAH}$, porém, diferentemente da $\mathrm{CAH}$, a teoria gerativa oferece uma perspectiva genuína para a questão da transferência com diferentes predições que não ficam no nível superficial das semelhanças e diferenças entre as línguas.

A associação da teoria gerativa à questão da transferência L1-L2 difere das abordagens anteriores em vários aspectos (WHITE, 1993, p. 455): em termos de

a) níveis, já que a teoria da gramática assume que a transferência pode atingir diferentes níveis representacionais sintáticos; 
b) grupo de propriedades, já que alguns parâmetros reúnem conjuntos de propriedades e, portanto, adotar a possibilidade da transferência paramétrica significaria adotar a transferência de tais conjuntos;

c) interação paramétrica, pois, aceitar que a GU atua na aquisição da L2 significa aceitar a presença de parâmetros, não necessariamente relacionados à L1 ou à L2, que podem compor a interlíngua, fazendo desta um sistema linguístico atípico em relação às duas e

d) considerações de aprendizagem, relacionadas, por exemplo, ao fato de que o princípio de marcação pode ser adotado para auxiliar nas predições sobre as formas que são ou não favorecidas na aquisição (p. ex. Eckman, 1977).

\section{Propostas gerativistas de teoria de aquisição em L2: um resumo}

É possível classificar as hipóteses defendidas nos trabalhos em SLA de linha gerativista, tendo por base as duas questões aqui apresentadas: 0 possível acesso à GU e a questão da transferência paramétrica, como vemos abaixo (GARRÃO NETO, 2006, p. 7):

(a) No Transfer / No Acess - hipótese defendida por aqueles que não acreditam na atuação da GU, tampouco na transferência paramétrica;

(b) No Transfer / Full Access - hipótese de que há apenas atuação da GU no processo de aquisição e nenhuma transferência da $L 1$;

(c) Partial Transfer / No Access - hipótese de que há transferência parcial da gramática da L1 sem atuação da GU;

(d) Partial Transfer / Full Access - hipótese de que há transferência parcial e acesso total à GU;

(e) Full Transfer / No Access - hipótese de que há transferência total e sem nenhum acesso à GU e;

(f) Full Transfer / Full Access - hipótese de que há transferência total da L1, além de total acesso à GU.

Como vemos, dentro de uma mesma linha teórica há diferentes visões a propósito de um mesmo assunto. Venturi (2006, p. 121) explica que: 
apesar de haver opiniões divergentes entre os próprios adeptos da teoria gerativista, uma explicação mais ou menos comum tem sido a de que a disponibilidade à GU não é tão óbvia em casos de aquisição de segunda língua por adultos. Ou seja, a aquisição de segunda língua depois da adolescência não é mais função da GU, mas é um processo cognitivo de aprendizagem de habilidades. Daí, explicam-se as fossilizações e julgamentos limitados de gramaticalidade.

Tudo isso mostra que a busca de explicações que abarquem um número importante de fatores relacionados à transferência na SLA não é simples. Tal busca talvez nem seja possível se não levarmos em conta, além de fatores linguísticos, fatores cognitivos e externos ligados à situação comunicativa e de natureza extralinguística. Apenas assim, em conjunto, tais fatores talvez contribuam para a formulação de uma teoria abrangente de aquisição/aprendizagem de L2, por contemplar as diferentes variáveis relacionadas ao assunto.

Apresentamos tal argumentação para justificar nossa opção por uma proposta que dê suporte não a uma visão de aquisição de L2, mas a de seu aprendizado, dada a limitação da formação de uma gramática genuinamente idêntica a da LA.

\section{A transferência e a perspectiva da sociolinguística variacionista}

Um ponto importante para estudos de SLA diz respeito aos aspectos sociolinguísticos envolvidos na produção da L2. Segundo Tarone (1988), observam-se os seguintes tipos de variação no discurso aquisitivo em L2 (adaptado de MORAES BEZERRA, 2003):

a) variação de acordo com o contexto linguístico;

b) variação de acordo com fatores psicológicos de processamento;

c) variação de acordo com o contexto social e

d) variação de acordo com a função da linguagem. 
A variação no uso de formas semanticamente semelhantes mostra que talvez a aquisição de determinada estrutura ainda não tenha ocorrido. Ao aplicarmos os pressupostos teóricos da teoria variacionista a teorias de SLA, encontraremos, inevitavelmente, instâncias de transferências explicáveis a partir de fatores que na L1 favorecem o uso de uma ou outra construção, influenciando a probabilidade de que determinada forma também apareça no discurso em L2.

Aos fatores listados por Tarone podemos ainda adicionar aqueles que tradicionalmente compõem análises variacionistas: idade, sexo, comunidade de fala e classe social. Tais fatores podem explicar, ou ao menos sugerir explicações, acerca das instâncias de transferências, positivas ou negativas, presentes no discurso individual dos aprendizes de L2.

Embora alguns teóricos acreditem que apenas a competência linguística seja importante para o entendimento da aquisição de uma L2, descartando abordagens que contemplem fatores relacionados ao desempenho do aprendiz, Mitchell e Myles (1998, p. 179) repudiam tal tendência e afirmam que o descarte da visão variacionista não seria apropriado para uma discussão ampla de SLA, por ela fornecer, por exemplo, valiosas informações sobre contextos de ocorrência de determinadas formas.

\section{Transferência e discurso}

No artigo From discourse to syntax: grammar as a processing strategy (1979), Givón argumenta que o curso de aquisição de L2 pode ser interpretado como um processo, ao qual o autor chama de sintaticização, em que a linguagem se torna menos suscetível a forças pragmáticas e de necessidade de comunicação, submetendo-se mais às pressões gramaticais da língua a ser adquirida. Segundo o autor, esta é uma trajetória que parte do modo pragmático em direção ao modo sintático de comunicação.

O autor apresenta estudos diacrônicos que revelam processos pelos quais passam as principais construções sintáticas das línguas. Tais processos, no campo da SLA, consistem na passagem de estruturas originadas por motivações discursivas que se tornam estruturas sintáticas cristalizadas, compactadas e gramaticalizadas. Nessa visão, a ordenação vocabular e a 
sintaxe são definidas a partir das necessidades discursivas dos usuários e, portanto, são mais flexíveis por conta dos condicionamentos discursivos, tornando-se mais rígidas após a fixação da gramática da $L 2$.

Também nessa proposta, podemos supor que a transferência exerce papel importante, visto que ela representa um processo estratégico-cognitivo presente no curso de aquisição da L1 que é reutilizado em contextos de aprendizado de L2. O uso do modo pragmático de comunicação está presente em estágios iniciais de aquisição de L1 e é transferido para a aquisição de uma L2 para ser utilizado de acordo com as necessidades comunicativas dos falantes, independentemente das implicações formais do idioma a ser adquirido.

O modo pragmático de comunicação estaria, então, presente nos processos de aquisição de L1 e L2 e corresponderia a um modo comunicativo inicial, cuja trajetória em direção ao modo sintático espelharia a trajetória das línguas em geral, em que verificamos o obscurecimento gradual da iconicidade.

Assim, tendo como base Givón (1979), assumimos que o discurso aquisitivo em $\mathrm{L} 2$ se assemelha ao discurso aquisitivo em L1, o qual, por sua vez, se constitui em um modelo mais dependente de estratégias comunicativas e que a $L 1$ dos adultos e a $L 2$ de falantes fluentes também se assemelham no sentido de serem mais planejadas e refletirem o uso de uma sintaxe menos frouxa, embora ainda suscetível, sob determinadas condições, a usos de estratégias discursivas, comuns ao modo pragmático de comunicação.

O aprendiz de uma L2 parece, então, se servir também de noções pragmáticas de comunicação e não apenas de estruturas sintáticas propriamente ditas. $\mathrm{O}$ modo comunicativo inicial traz à tona características do arcabouço pragmático/cultural dos falantes e é utilizado em contextos que se assemelham aos que outrora eles foram expostos, fazendo desse fenômeno uma instância de transferência. Falamos aqui de situações de stress comunicativo, falta de background pragmático partilhado e contexto imediatamente óbvio, situações que não propiciam discurso controlado, ou seja, mais gramaticalizado ou sintaticizado.

Pode-se dizer, então, que no campo do fenômeno das transferências linguísticas entre L1 e L2 também se encontra, além de questões fonéticofonológicas, sintáticas e semânticas, a transferência de aspectos discursivos, 
provenientes da $\mathrm{L} 1$, que guiam o usuário da língua através do discurso e segundo suas intenções. Em suma, parece que o próprio modo de comunicação pragmático, que permanece latente na codificação linguística do falante nativo, também é transferido para o discurso em segunda língua durante os diferentes estágios de estabilização da gramática da L2. Falantes de um segundo idioma transferem para a L2 o uso do modo pragmático de comunicação para dar conta de suas necessidades comunicativas.

A análise sobre a transferência de traços da língua materna na aquisição de uma segunda língua deve, assim, contemplar também questões do campo discursivo. Uma teoria que deseja tratar do processo de aquisição de L2, a partir de uma perspectiva global, não poderá se deter apenas ao nível sentencial, mas se organizar segundo o princípio de que a linguagem é um "instrumento de interação social empregado por seres humanos com o fim primário de estabelecer relações de comunicação entre interlocutores reais" (PEZATTI, 1994, p. 38). Isto também mostra a necessidade de incorporarmos ao campo da SLA outras disciplinas e teorias que possam explicar melhor as diversas questões relacionadas ao assunto. Foi assim que propostas interdisciplinares, desenvolvidas principalmente no âmbito da Linguística Aplicada, surgiram como fonte de investigação do fenômeno da aquisição em L2.

\section{Transferência sintática}

A ordenação vocabular é tradicionalmente uma importante área de estudos de SLA. Estudos sobre ordem contribuem não apenas para 0 entendimento de pontos centrais quanto à transferência L1-L2, em si, mas também para o entendimento de questões discursivas, de tipologia linguística e outros fatores envolvidos na SLA.

De acordo com Odlin (1989, p. 85), grande parte das línguas apresenta as ordens VSO, SVO ou SOV como ordenação básica, apesar de variarem em termos de rigidez / flexibilidade de seus usos. Para o autor, o grau de rigidez de uso das formas pode ser transferido no curso de aquisição de L2. Obviamente, isso fará com que falantes de línguas com maior flexibilidade de 
ordenação possam apresentar 0 uso de diferentes possibilidades de ordenações apesar da LA apresentar um sistema de ordenação mais rígido.

Parece claro também que a rigidez de ordenação afeta não apenas questões de produção, mas também de compreensão e inteligibilidade. $\mathrm{O}$ estudo de Gilsan (apud ODLIN, 1989, p. 87), por exemplo, mostra que falantes de inglês, aprendizes de espanhol como L2, apresentam dificuldades de compreensão, associadas ao menor grau de rigidez sintática da língua adquirida.

\section{Discurso, sintaxe e transferência}

Se, por um lado, em termos de percepção, o uso de ordenação mais rígida auxilia a aquisição, por outro, a ordenação vocabular mais flexível pode sinalizar tentativa de simplificação do processamento linguístico. A ordenação maleável pode indicar possibilidades discursivas transferidas da L1 ou ainda indícios discursivos presentes em todas as línguas (Odlin, 1989, p. 88). O trabalho de Freitas (2006), por exemplo, mostra que o uso da ordem VS, em inglês, por aprendizes brasileiros, indica forte transferência proveniente da L1 de um recurso discursivo de introdução de novos tópicos no nível do discurso.

Sobre esse assunto, Odlin afirma que o próprio termo "ordenação vocabular livre" pode ser equivocado, se pensarmos que mesmo línguas de suposta ordenação livre apresentam condicionamentos discursivos que favorecem determinadas ordens em detrimento de outras. $\mathrm{Na}$ verdade, os usos dessas ordens podem ser explicados por motivações ou restrições específicas das línguas, em geral, transferidos para o processo de SLA.

Algumas dessas restrições são evidentes nos limitados padrões de definição de tópico discursivo. Vale lembrar que a noção de tópico não deve ser confundida com a noção de sujeito, embora a interrelação entre estas entidades seja previsível e, de fato, frequente. Deve-se, no entanto, estabelecer que a noção de tópico esteja, na verdade, inversamente associada à noção de foco informacional, tanto na escrita quanto na língua falada. O que o falante elabora acerca do tópico é denominado comentário e frequentemente é organizado no discurso segundo a ordem tópico-comentário, a qual também frequentemente coincide com a ordem sujeito-verbo em diversas línguas. 
No que diz respeito à SLA, Odlin (1989, p. 88) afirma que, para minimizar a dificuldade de se estabelecer o tópico de determinado trecho discursivo, o falante-aprendiz de uma L2 usa mais a ordem tópico-comentário em seu discurso. Conforme mostra Givón (1984), quando o falante apresenta dificuldade de estabelecer um novo tópico discursivo, ou quando ele prevê que o ouvinte possa ter essa dificuldade de percepção, ele utiliza a estratégia de assegurar o papel do tópico no discurso e só então apresentar a informação nova. Para Odlin, há diversas evidências de que aprendizes de L2 em estágios mais iniciais de aquisição utilizem mais a ordem tópico-comentário. Mesmo estudos que sugerem que isto seria uma transferência de um tipo de ordenação comum na L1 não se constituem em contra-argumentos para esta afirmação, visto que muitas pesquisas mostram que o uso da ordem tópicocomentário nem sempre aponta para influência da L1 (ODLIN, 1989, p. 89).

Tratando da interface transferência e sintaxe em L2, Givón (1984) estabelece princípios universais de inclusão e continuidade de tópico, mostrando que o uso de ordens tais como VS, VO, SV e OV pode não ser aleatório, mas motivado. Segundo Givón (op. cit.), "[d]os tópicos plenos, expressos por uma palavra independente ou pronome, os que forem mais contínuos ou previsíveis apresentarão a ordem comentário-tópico (VS, VO), enquanto os menos contínuos e previsíveis apresentarão a ordem tópicocomentário (SV, OV)".

Apesar desta tendência translinguística, alguns trabalhos mostram que muitos dos erros são reconhecidamente de transferência e que nem sempre estes universais acompanham de modo amplo as questões de tópico em L2. Além do mais, estudos comparativos de Granfors e Palmberg (ODLIN, 1989, p. 91) sugerem que falantes nativos de L1 com ordenação vocabular rígida tendem a cometer menos erros de ordenação do que falantes de línguas de ordenação mais flexível.

Propostas com orientações discursivas, sociolinguísticas e inatistas podem não tratar da questão da transferência sintática da mesma forma. A questão da transferência é discutida, entretanto, em todas as propostas teóricas, ora por orientações mentalistas de aquisição de L2, ora por orientações acerca de universais de organização discursiva típicas de estágios aquisitivos iniciais de L2. Em todas elas, por mais adequados que possam 
parecer certos contra-argumentos, o que se sabe é que as pesquisas que tratam da transferência de padrões de ordenação vocabular terão sempre papel de destaque, quando contribuírem, tanto no plano teórico como no empírico, para o entendimento da aquisição de uma L2.

Lembramos que associados aos fatores estruturais e discursivos que possam estar envolvidos na transferência sintática, encontram-se também questões que podem inibir a transferência. Fatores como o conhecimento de mundo, sistêmico e linguístico do indivíduo, além de questões de natureza sociolinguística, podem representar forte argumento contra certas propostas comparativas, como as análises contrastivas menos analíticas, por representarem argumentos contra previsões formatadas.

\section{A Hipótese do Período Crítico e a Fossilização}

A Hipótese do Período Crítico (HPC) de Lennberg (1967), embora não originária de estudos linguísticos, é uma das mais utilizadas nos estudos de aquisição de L1 e L2 (FERRARI, 2007).

De acordo com Ellis (1997, p. 67), a HPC supõe a existência de um período específico, em que a aquisição de uma língua seja possível e que fora dele ela seria dificultada e incompleta. Para justificar sua existência, toma-se por base a atuação principalmente de mecanismos inatos na aquisição da linguagem, posto que este período de tempo seria biologicamente determinado ${ }^{1}$.

Pesquisas em SLA apontam para a possibilidade de extrapolação da HPC para contextos aquisitivos de L2. O pressuposto que tentam estabelecer é o de que existe um período crítico para aquisição de uma $L 2$, o qual ocorreria até a puberdade e para além do qual aprendizes não seriam verdadeiramente capazes de adquirir a gramática de uma L2, tal como um falante nativo (BROWN, 1994, p. 53).

Existem evidências importantes que favorecem a incorporação da HPC nos estudos de SLA. Segundo Ellis (1997, p. 68), indivíduos que emigram para

\footnotetext{
${ }^{1}$ A hipótese é baseada em pesquisas que mostram como pessoas que sofreram acidentes antes da puberdade e perderam suas capacidades linguísticas as recuperaram após o acidente, o que não acontece com as que sofreram após a puberdade (Ellis, 1997, p. 67).
} 
os EUA antes da adolescência adquirem o idioma nativo, alcançando níveis de proficiência, tanto no nível da gramática quanto no fonológico, muitas vezes indistinguíveis da proficiência nativa, o que não acontece com os que emigram mais tardiamente.

Existem, entretanto, evidências de que algumas pessoas não são condicionadas por questões etárias no que concerne à aquisição de L2. O autor cita casos de indivíduos que apresentaram performance oral em L2 similar a de nativos, apesar de terem adquirido o idioma na fase adulta. Diversos fatos indicam que a $L 2$ pode ser adquirida com igual competência de uma L1, mesmo por adultos, se o input for robusto e não ordenado. Casos como o do escritor Joseph Conrad, polonês, naturalizado inglês, e que dominava perfeitamente a sintaxe da língua inglesa, tornando-se romancista nesse idioma, favorecem essa possibilidade.

Portanto, tais considerações apontam para uma possível inadequação do conceito de período crítico, ao menos, nos termos em que é costumeiramente apresentado. Por exemplo, a aquisição do nível fonético e sintático acontece de modo diferenciado, pois muitas vezes, embora indivíduos adultos apresentem aparente domínio sintático do segundo idioma, no nível fonéticofonológico, eles continuam apresentando indícios, quase sempre importantes, de transferência e influência da $L 1^{2}$. Tantos indícios contra uma formulação forte acerca da HPC fizeram com que hoje falemos em período sensível em vez de período crítico para aprendizagem de línguas.

Com a hipótese do período sensível não seria possível ao indivíduo não nativo adquirir, em termos de competência linguística, de modo integral e homogêneo a L2, posto ser isso possível apenas nos primeiros anos de vida do homem. Dadas as evidências relacionadas à melhor ou pior performance de indivíduos de diferentes faixas etárias, postula-se que até determinada idade 0 'aprendizado' de uma L2 seria mais facilitado, quando comparado ao aprendizado de indivíduos mais velhos. A hipótese do período sensível passa a ser interessante por não impor condições absolutas para a explicação do

\footnotetext{
2 Podemos dizer que mesmo a sintaxe não reflete a real produção do nativo, sem consideramos ainda os níveis discursivos e pragmáticos que fortemente interagem e ainda podem apresentar indícios de transferência da L1. Eis aqui a justificativa para nossa posição em favor do conceito de aprendizado e não de aquisição de L2.
} 
processo de SLA, já que não impede a explicação de fenômenos menos frequentes, como o caso 'Joseph Conrad'.

Faz-se necessário abordar aqui o termo fossilização. Recorrente na literatura em SLA e formulado inicialmente por Selinker (1972), o termo diz respeito ao uso frequente, ao longo do desempenho da $L 2$, de construções não apenas anômalas às construções da L2, mas também de difícil alteração no discurso do aprendiz, não importando o grau de exposição ao input. Trata-se de um conceito que se aproxima da noção de estabilização, embora trate especificamente de formas incorretas e explicáveis a partir de diversos princípios, dentre eles, pela transferência. Em outras palavras, a fossilização apontaria para a cristalização da interlíngua, o que é evidenciado pela dificuldade de que a gramática do aprendiz evolua em direção ao modelo a ser adquirido,

Propostas como a do período sensível e a da fossilização confirmam as diferenças que se dão no campo de aquisição L1-L2 e mostram que a questão da transferência pode atuar de modo diferenciado em cada nível da gramática e em cada indivíduo, evidenciando a posição instável da noção de aquisição em detrimento à noção de aprendizado.

\section{Conclusões}

Tendo em vista os pontos aqui apresentados, podemos dizer que qualquer teoria de aquisição de L2 necessariamente deverá ser multidisciplinar. As descobertas nesse campo de pesquisa mostram que é necessário conjugar variáveis linguísticas e individuais de seus aprendizes. Em outras palavras, o estudo da SLA deve ser conduzido por uma visão ampla de análise dos fenômenos.

Segundo Long (1994, p. 480), aqueles que buscam explicar a aquisição de uma L2 por uma única perspectiva teórica tornam as análises potencialmente incompletas, ou mesmo, ineficazes. Para o autor, oito condições para o desenvolvimento de uma boa abordagem de SLA podem ser definidas, algumas citadas abaixo:

a) padrões desenvolvimentais de aquisição reconhecidos no discurso de diferentes aprendizes e sob diferentes condições de aprendizado mostram que 
qualquer teoria que não contemple a atuação de universais na relação língua/cognição é incompleta ou inadequada;

b) diferenças quanto ao tempo de aquisição e o nível de proficiência de crianças e adultos em situações de aquisição semelhantes exigem que a teoria especifique diversos mecanismos desenvolvimentais, a partir da idade em que se inicia o processo de aquisição, além das diferentes formas como esses mecanismos são acessados;

c) uma teoria que explica o desenvolvimento da interlíngua com base somente em fatores afetivos pode estar apenas lidando com questões mais ou menos facilitadoras do processo de aquisição, mas que não necessariamente construam uma teoria de aquisição;

d) o fato de que algumas construções linguísticas exigem atenção específica para fins de aprendizado mostra que uma teoria que assegura o processo de aquisição como fator inconsciente será inadequada;

e) a impossibilidade de aprendizado de alguns fenômenos da L2 apenas pela evidência positiva mostra que uma teoria que defende que a aquisição acontece somente pela exposição à língua alvo pode ser inadequada e f) a sistematicidade da interlíngua, sua trajetória desenvolvimental e produção sistemática de construções não típicas da LA indicam uma contribuição cognitiva forte por parte do aprendiz e mostram a inadequação de teorias comportamentais.

Savignon (1983, p. 57) também defende uma visão múltipla do processo de SLA. O autor agrupa as variáveis de aprendizagem em quatro macro categorias. Segundo o autor, ao abordarmos a questão da aquisição de uma L2, devemos olhar para:

a) quem aprende, pois se deve considerar certas idiossincrasias do aprendiz, tais como, sexo, idade, cognição e conhecimento de mundo em geral;

b) o que é aprendido, considerando-se a questão da competência comunicativa, numa proposta ampla que englobe a competência gramatical, sociolinguística, discursiva e estratégica;

c) onde se aprende, já que contextos e situações comunicativas impactam o de aprendizado da L2 e 
d) como se aprende, levando em conta estratégias e processos que permeiam a aprendizagem (p. ex. o grau de identificação com a L2, estilos de aprendizagem e abordagens de ensino).

Estas parecem ser propostas que alcançam certo equilíbrio quanto não apenas ao papel da transferência, mas também ao processo aquisitivo mais geral: suas implicações, restrições e fatores facilitadores. Mostram que a interatividade de fatores envolvidos no processo será de real importância para seu entendimento, restringindo o desenvolvimento de abordagens singulares, quase sempre limitadas, do assunto.

Calcados nesta visão, a de que a abordagem deve ser multidisciplinar e abrangente, é que defendemos o uso de modelos de análise que contemplem sempre a atuação de variáveis formais e funcionais no curso de aquisição de uma L2. Sem um posicionamento que abarque diferentes possibilidades de fatores atuantes no processo, dificilmente chegaremos a respostas plausíveis sobre fatos empiricamente verificáveis e que demandam tratamento científico adequado.

\section{Referências bibliográficas}

BROWN, D. Principles of language learning and teaching. New Jersey: Prentice Hall, 1994.

CHOMSKY, N. Some Methodological Remarks on Generative Grammar. Word: 219- 239, 1961

. Principles and Parameters in syntactic theory. In: Horstein and Lightfoot (eds). Explanation in Linguistics. 1981.

ECKMAN, F. Markedness and the contrastive analyses hypothesis. In: Language Learning. 27: 315-330. 1977.

ELLIS, R. Second Language Acquisition. Oxford: Oxford University Press, 1997.

FERRARI, M. A Hipótese do Período Crítico no aprendizado da língua estrangeira analisada à luz do paradigma conexionista. Tese de Doutorado. PUC-RS, 2007

FREITAS, Roberto de. Reflexos pragmático-discursivos da L1 na aquisição de inglês como L2: um estudo sobre o uso da cláusula VS. Dissertação de Mestrado. UFRJ: Rio de Janeiro. 2006. 
A constituição discursivo-gramatical da construção (X)VS em inglês como L2: indícios de formação da interlíngua. Tese de Doutorado em Linguística. Faculdade de Letras, UFRJ, 2011.

GARRÃO NETO, E. M. Sujeito Pleno e Sujeito Nulo na aquisição do Português Brasileiro e do Português Europeu como segunda língua: evidências para o estudo da interlíngua. Tese de Doutorado em Lingüística. UFRJ: Rio de Janeiro, 2006.

GIVÓN, T. On understanding grammar. New York: Academic Press, 1979.

GILSAN, E. The effect of word order on listening comprehension and pattern retention: an experiment in Spanish as a foreign language. Language Learning 35: 443-72. 1985

. Universals of discourse structure and second language acquisition. In: Universals of Second Language Acquisition, ed. By William Rutherford. Amsterdam: John Benjamins. 1984.

HYMES, D. Foundations in Sociolinguistics: An Ethnographic Approach. Philadelphia: University of Pennsylvania, 1974.

LEMNEBERG, E. H. Biological Foundations of Language. Wiley. New York: 1967.

LONG, M. The least a second language theory needs to explain. In S. Gass \& L. Selinker (eds). Language transfer in language learning, 217-32. Rowley, Mass.: Newbury House. 1993.

MITCHELL, R.; MYLES, F. Second Language Learning Theories. London: Arnold Publishers, 1998.

MORAES BEZERRA, I. C. R. Prática Exploratória: um caminho para o entendimento. Pesquisas em Discurso Pedagógico. Rio de Janeiro, Departamento de Letras - PUC-Rio, v. 2 (2), 2003.

ODLIN, T. Cross-linguistics influence in language learning. Cambridge: Cambridge University Press. 1989.

PEZATTI, E. Uma abordagem funcionalista da ordem de palavras no português falado. São Paulo: Alfa, 1994.

SAVIGNON, S. Communicative Competence: theory and classroom practice. Addison-Wesley, 1983.

SELINKER, L. Interlanguage. International Review of Applied Linguistics, v. 10, p. 209-231, 1972. 
e LAMENDELLA, J. The role of extrinsic feedback in interlanguage fossilization: A discussion of "Rule fossilization: A tentative model." Language Learning 29: 363-375. 1979.

STENSON, N. Induced errors. In: New Frontiers of Second Language Learning. Mass.: Newbury house, 1974.

TARONE, E. Variation in Interlanguage. London: Edward Arnold,1988.

VENTURI. M. A. Aquisição de língua estrangeira numa perspectiva de estudos aplicaddos. In: Aquisição da Linguagem: uma abordagem psicolingüística. São Paulo: Contexto, 2006.

WHITE, L. 'Universal Grammar: Is it just a new name for old problems?' In: S. Gass e L. Selinker (eds). Language transfer in language learning, 217-32. Rowley, Mass.: Newbury House, 1993. 
Artigo recebido em: 03 de outubro de 2013

Artigo aprovado em: 10 de novembro de 2013

\section{Sobre o autor:}

Roberto de Freitas Junior é Doutor e Mestre em Linguística pela UFRJ e especialista em língua inglesa pela PUC-Rio. Professor da Faculdade Gama e Souza (FGS), da Faculdade Mercúrio (FAMERC), da rede municipal de ensino do RJ e sócio coordenador do CCAA Bonsucesso. Professor colaborador do grupo Discurso e Gramática (D\&G) da UFRJ e publicou o artigo "O Sujeito posposto no PB: Inacusatividade e Estrutura Informacional", Revista da Gama e Souza, v. I, p. 37-43.em 2011. 